\title{
Blood Supply Chain Risk Management using House of Risk Model
}

\author{
Wijai BOONYANUSITH ${ }^{1}$ and Phongchai JITTAMAI, ${ }^{2, *}$ \\ ${ }^{1}$ School of Information Technology, Suranaree University of Technology, \\ Nakhon Ratchasima 30000, Thailand \\ ${ }^{2}$ School of Industrial Engineering, Suranaree University of Technology, \\ Nakhon Ratchasima 30000, Thailand
}

('Corresponding author's e-mail: jittamai@sut.ac.th)

Received: 19 January 2017, Revised: 9 January 2018, Accepted: 6 February 2018

\begin{abstract}
Managing blood supply chain has been an important task in the healthcare system because it has to confront not only blood demand and supply uncertainties but also complexities in blood inventory management. In order to overcome these challenges, it is essential to explore the possible risks that could occur in the blood supply chain and discover proper ways to manage these risks. Therefore, this research aims to investigate risks in blood supply chain by using a proactive risk management tool called 'house of risk' (HOR) model, in order to conduct risk assessment and evaluate risk management actions. A case study of blood supply chain risk management was analyzed, and the HOR model was incorporated to appraise the appropriate actions in the real situation. The results indicate that there are 30 risk events and 16 risk agents identified and assessed in the case study. The outcomes point out that lack of collaboration, insufficient information for decision-making, and limited information sharing are the top 3 risk agents that contribute to significant impact on blood supply chain management. Risk mitigation and management actions were evaluated and the results show that enhancing the collaboration is the most proactive action to manage risks in the blood service operations, followed by information sharing, and demand and supply statistical analysis. The study has recommended the outlines for improving collaboration between blood service organizations by using information system and technology to mitigate risks, complexities, as well as uncertainties in managing demand and supply in the blood supply chain.
\end{abstract}

Keywords: Risk assessment, supply chain risk management, house of risk model, blood supply chain

\section{Introduction}

Supply chain management has played a significant role to strengthen the healthcare service system. The growing health service demands have become key drivers to improve operation efficiency and effectiveness as well as to achieve cost reduction and ensure quality of care [1]. The healthcare supply chain management is much more complex than those in other industries. It has a greater degree of variation because it deals with a variety of products, services, and medical practitioners. Moreover, unforeseeable demands make the medical supply management too difficult to respond to the needs of the patient. Consequently, the uncertain nature in the healthcare supply chain contributes to the occurrence of risks which have direct impacts on people's lives. Managing healthcare supply chain risks nowadays has been so sophisticated that it has drawn attention from both researchers and practitioners to explore. However, most research has focused on the medical and health risks with no integration of the risk management in organizational and operational structures reported in the literature [2].

There are several types of supply chain risks classified in the literature. The Supply Chain Operations Reference (SCOR) model has been utilized to classify those risks into 14 categories that describe the vulnerabilities to which a supply chain can be exposed [3]. Healthcare industry is so dynamic 
http://wjst.wu.ac.th

that it generates risks in the clinical care issues as well as the business issues such as financial, operational, and organizational risks. Moreover, risks in the healthcare supply chain are likely to cause greater effects than those in the other industries because they have significant impacts on patient's mortality [4]. Basically, the healthcare supply chain is driven by several manufacturing and service organizations to deliver services for patient care. Supply chain risks can be exposed to any operations in the healthcare network which would lead to inefficient management, increased operating costs, and inability to deliver sufficient services to the patient. For instance, blood transfusion is needed immediately to save the patient's life in most emergency cases. Delay risk in responding to blood acquisition could affect the treatment and lead to the fatality of the patient. Moreover, there are many types of patients who need blood for their cures such as cancer, anemia, and thalassemia patients. Risk in blood shortage would cause the doctors to postpone the patient's operations, which could in turn be harmful to their physical and mental health.

According to the aforementioned risks, blood is considered one of the most important medical resources in the healthcare operations. Demands of blood usage are uncontrollable. Blood supply is acquired only from voluntary donors, and blood products are high variation and perishable, which make matching between supply and demand as well as managing the blood inventory such complicated tasks. Hospital blood bank has major responsibility to manage and utilize blood in the inventory in order to avoid blood supply shortage and blood expiration. Blood Center has to provide safe, secure, and correct blood products to hospitals in the network [5]. However, Blood Center has to manage blood collection and distribution in the complex and uncertain environment which could possibly generate potential risks to the blood supply chain network.

\section{Statement of the issue}

Blood service operations are important in the healthcare system [6]. Practically, blood service operations mainly involve blood collection, processing, inventory management, distribution, bloodbanking management, and transfusion [7,8]. Blood Center collects whole blood from donors, processes it into blood products at the Regional Blood Center and distributes them to hospitals in the network in order to transfuse to patients in need. The main objective is to maximize blood utilization in such a way that blood shortage and outdate rates are minimized. Most research in the blood supply chain literature has focused mainly on the operations research discipline to study the ways to improve blood flow operations by using simulation [9], optimization models [10-13], and statistical analysis [14,15].

Two common performance measures to assess blood management are the numbers of blood shortage and of outdated units in the network [16]. Blood shortage would cause the postponement of any patient's treatment. In some emergency cases, the lack of blood supply could lead to an increasing rate of fatality of the patient. The expiration of blood would cause an additional cost for blood disposition. Practically, blood service professionals have focused on the safety and the quality issues of handling blood in the supply chain. There are several potential risks associated with the blood operations which could affect the overall performance in the healthcare network. However, there are a very few numbers of studies that discuss the issue of risk in the blood supply chain. Thus, this research aims to conduct a thorough investigation of risk management in the blood supply chain using a proactive risk management model in order to perform risk assessment and evaluate management actions to mitigate those risks.

\section{Materials and methods}

This work initially provides brief details of risk definition and risk management along with the implication of risk assessment in the supply chain perspective. The descriptions of blood supply chain operations are presented in order to investigate the potential risks in the network. A proactive risk management model was proposed as a tool to assess such risks. A case study of risk management in blood supply chain in Thailand was examined in order to exhibit the application of the risk management model in the blood supply chain. 
http://wjst.wu.ac.th

\section{Risk and supply chain risk management}

The risk definition could be a challenge to both academics and practitioners [17]. Risk itself is frequently defined as functions of probabilities and consequences of uncertain outcomes [18]. According to the supply chain perspective, March and Shapira [19] proposed the most well-known definition of risk as the variations in the distribution of possible supply chain outcomes, their likelihoods, and their subjective values. These variations affect the flows of information, materials, and/or finances throughout the supply chain network. They must be managed effectively in order to mitigate the impact of risk outcomes [20]. Tummala et al. proposed the risk management process (RMP) approach which comprises risk identification, measurement, assessment, evaluation, and monitoring [21]. The main objective is to identify and assess risks and evaluate the mitigation plan in the environment. The RMP approach has become an essential tool for risk management in a supply chain. The purpose is to manage the potential risks by evaluating their likelihood of occurrences, exposures, as well as triggers and losses [22]. The evaluation of risk management could provide guidelines to perform risk mitigation actions. Therefore, risk management is an important approach to handle uncertainties in complex supply chain management.

Several researchers have conducted literature reviews on supply chain risk management (SCRM) over the past 2 decades. Juttner et al. illustrated the concept of SCRM and identified an agenda for future research [23]. Vanany et al. employed a taxonomy review to investigate the SCRM literature which emphasized the methodologies and the risk discovery [24]. Rao and Goldsby reviewed the literature on SCRM and developed a typology of risks to assist vulnerabilities identification in the supply chain [25]. Colicchia and Strozzi also reviewed the literature to identify the growing patterns and trends in SCRM [26]. These works have provided useful guidelines for researchers to make a clear understanding and conduct ongoing research in the SCRM. Moreover, the main principle of SCRM is to identify, assess, and prioritize supply chain risks in order to minimize, monitor, and control the occurrences and the impacts of uncertain risk events [27]. There are numerous risk issues considered by researchers such as supplier inefficiency [28], demand fluctuations [29], capacity and information [30], inventory [31], and outcome uncertainty [32]. Also, there are several risks in operating the whole supply chain such as risks in external and internal activities [33], as well as material, financial, and information flow risks [34,35]. Furthermore, the study in SCRM should be addressed in 2 dimensions, which are supply chain risks and mitigation approaches [36]. Thus, understanding the nature, sources and causes of supply chain risks would contribute to an effective risk assessment and improved prioritizing the risk mitigation actions.

\section{SCRM models}

The SCRM has been developed based on the RMP approach in order to manage risks in supply chains [37]. The SCRM models have been widely incorporated in various industries ranging from advanced production to consumer goods manufacturing industries [38-43] as well as service industry $[44,45]$. Moreover, some analytical methods such as simulation, stochastic model, and analytical hierarchy process (AHP), have been incorporated to the SCRM in order to manage the risk in some complex supply chains, such as dental and medical supplies [46], maritime transportation [47], and global supply chain [48]. In term of risk in healthcare supply chain, there are not many studies found in the literature. Hemaida [49] developed a risk-based audit plan for a local hospital based on multifactor evaluation process. The results can be used to support the manager to reduce the operational risks in the hospital. Kavanagh and Cowan [50] examined the risks in healthcare team and provided an overview to reduce such risks. Okoroh et al. [51] studied the RMP in healthcare operation aspect using artificial neural network technique. This work provided an awareness which can support healthcare managers to evaluate the severity of risks on healthcare facilities operations. Ágoston et al. applied a quality risk management to identify and control potential risks in terms of quality and safety issues in the blood supply chain [5]. Nagurney et al. [6] developed multicriteria system-optimization model to capture the critical issues related to blood service operations including supply-side risk in procurement. However, there is a lack in the study of risk management in the blood supply chain which can contribute to the overall process in the network. Thus, the objective of this research is to examine the associated risks in blood supply chain management based on a practical SCRM approach in order to assess such risks and to prioritize the preventive actions. 


\section{Blood supply chain network and its operations}

Blood bank service is established in order to provide safe, secure, affordable, and available supply of blood products from donors to hospitals in the region. Each hospital has a blood bank which has major responsibilities for blood operations management in order to provide blood products for patients' treatments. There are 3 main models to manage regional blood supply chain: (1) single center model; (2) multiple independent centers model; and (3) coordinated multiple centers model [52]. The single center model is a single community blood center which serves the entire demand of all hospitals in the region. The multiple independent centers model is a group of collaborative community blood centers which serve the blood demand of all hospitals in the region. Also, the coordinated multiple centers model is a regional blood center which operates the activities of a group of community blood centers in order to fulfill the needs of the hospitals in the region. According to these 3 networks mentioned above, there are 2 commons stakeholders in these 3 models, namely the Regional Blood Center (RBC) and the Hospital Blood Banks (HBBs).

The flows in this supply-to-demand system consist of several logistics operations between RBC and HBBs. The main activities of RBC are blood collection, processing and testing, component production, inventory management, and allocation/distribution to the HBBs in its responsible region. Blood collection is a process to collect the whole blood from donors, including volunteer donor recruitment and promotion. Whole blood units are collected and tested in the laboratory for infectious agents. Blood units that pass inspection will be processed into blood products and then stored in the inventory. Each RBC is responsible for managing this inventory and allocating available supply units to hospitals according to requisitions from the HBBs. The main processes of a regional blood center are shown in Figure 1.

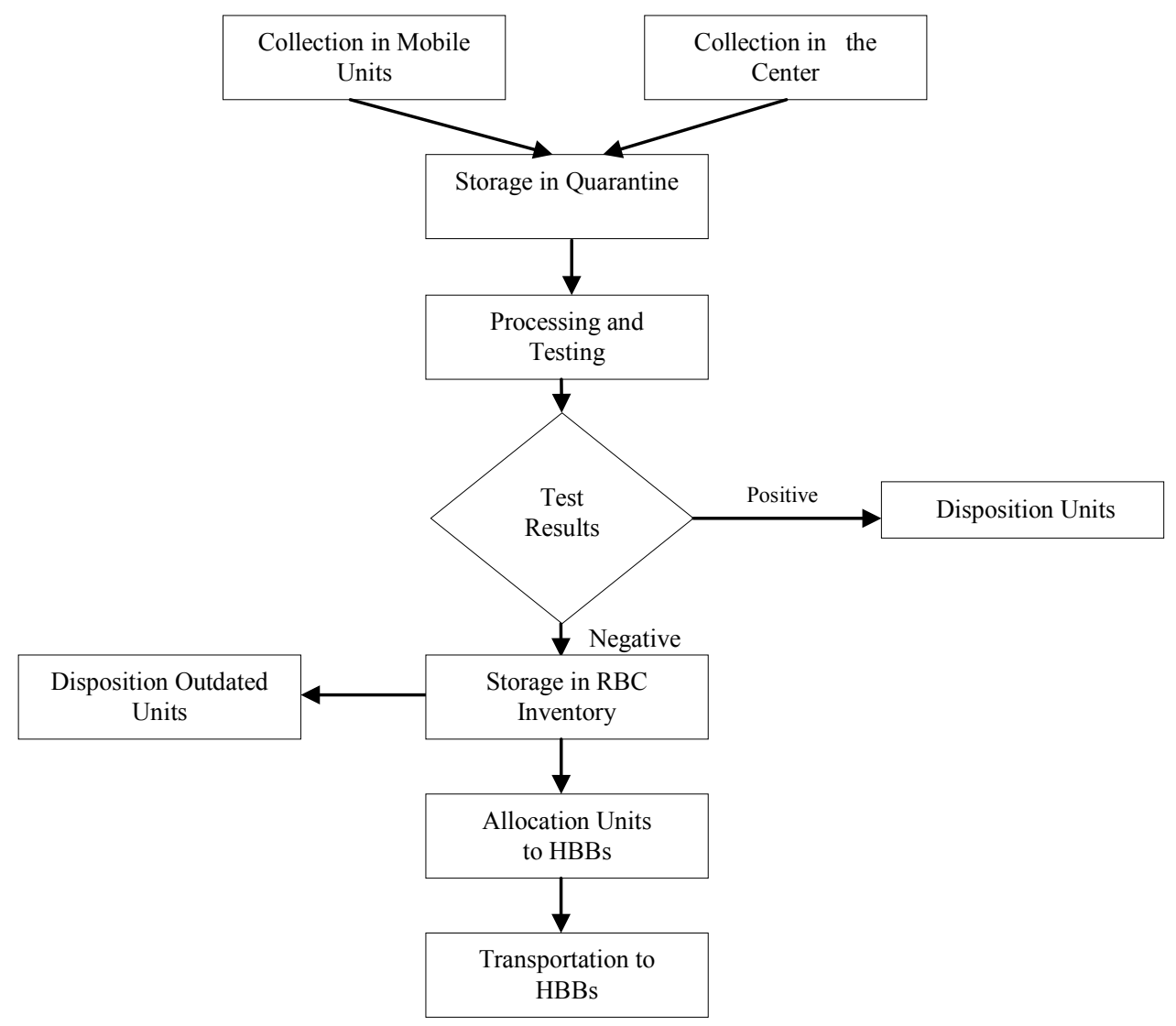

Figure 1 Main processes of a regional blood center in the blood supply chain 
http://wjst.wu.ac.th

Each HBB has to conduct blood inventory and operation management within the hospital. Doctors are responsible for determining the quantity and groups of blood products required for patient's treatment. When available blood products are assigned for any patient, these units will be tested for crossmatching to verify the blood compatibility with that patient. After crossmatching, blood will be stored in the assigned inventory in blood bank. Practically, these crossmatched units may not always be used because the doctors may postpone operations or there are blood units left after patients' treatments. These untransfused blood units will be returned to the unassigned inventory if they do not expire. The duration between assigning blood to a particular patient and releasing any unused units back to the inventory is called the "crossmatched release period" (CRP). CRP is considered as a period for reserving blood. The longer the CRP is, the higher probability it will be for the blood to expire before its use. The crossmatched units will be transfused to the patient for treatment, and the patient will be periodically examined for any transfusion reactions. The main processes of a hospital blood bank are shown in Figure 2.

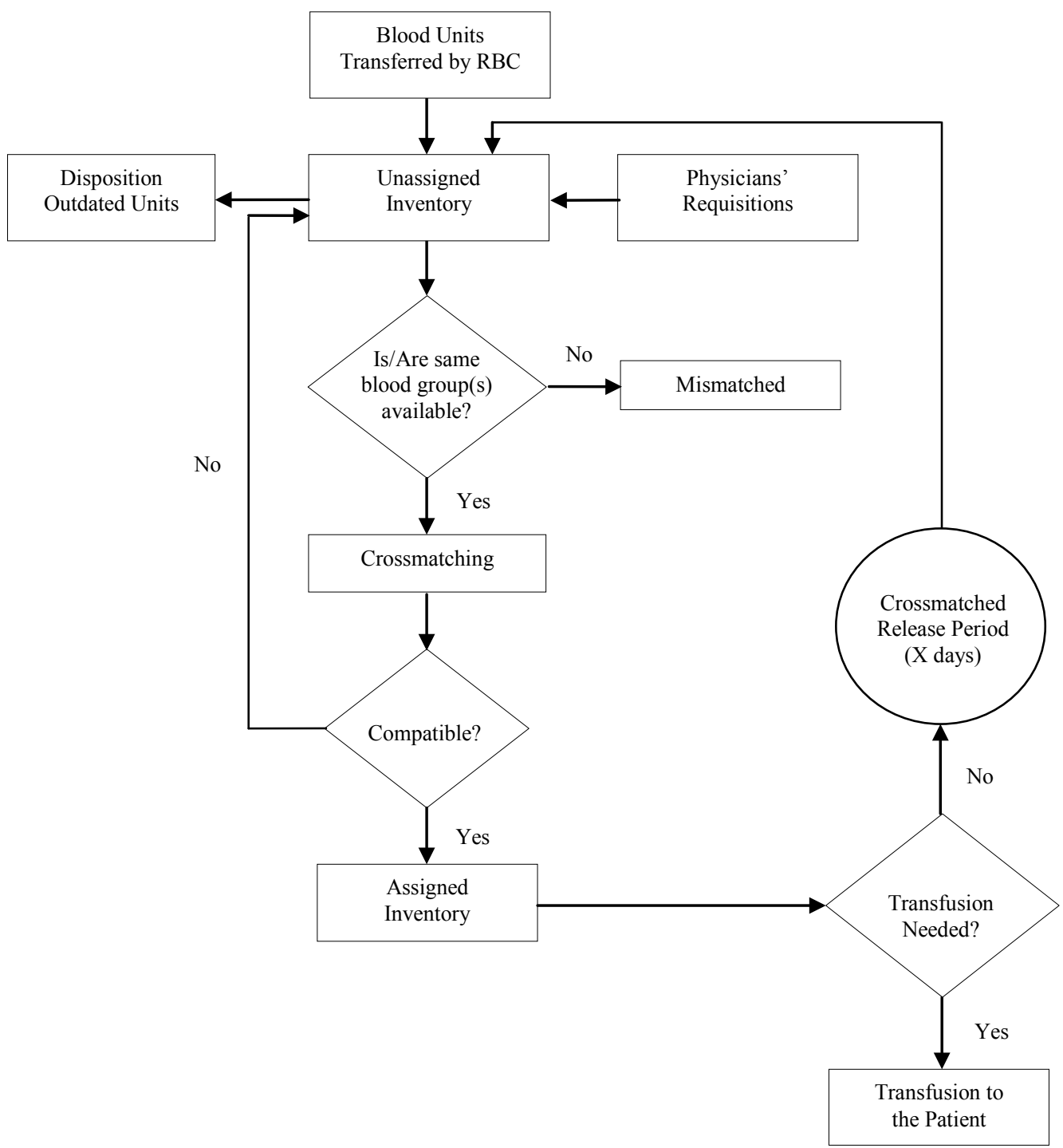

Figure 2 Main processes of a hospital blood bank. 
http://wjst.wu.ac.th

\section{Blood supply chain management}

Most research in the blood supply chain literature has focused mainly on the operations research discipline. Several authors have applied simulation and optimization models as well as statistical analysis to study blood operation problems throughout the entire supply chain. Pierskalla [7] studied on the supply chain management of blood banks, including a strategic overview of the blood banking supply chain and a discussion of a number of tactical and operational issues involved in this system. Katsaliaki [53] simulated models of alternative policies in order to identify good practices that lead to cost reduction and increased safety of the blood supply chain in the UK. Rytilä and Spens [54] aimed to increase efficiency in the blood supply chain by using simulation method to compare alternative operational policies in the blood supply system in Finland. Delen et al. [55] presented a novel application of operations research, data mining and geographic information-systems-based analytics to support decision making in the blood supply chain management. Fontaine et al. [56] analyzed the platelet supply chain performance to establish an improved inventory management approach through collaboration between blood centers and hospital transfusion services. Katsaliaki and Brailsford [8] analyzed policies for managing the blood inventory system between a hospital and a regional blood center in order to determine improved procedures and outcomes, leading to shortage and wastage reductions, increased service levels, and reduced costs.

The aforementioned review shows that the blood supply chain concept is essential to deliver safe, affordable, and available supply of blood products from donors to patients in the network. Its performance could be improved through collaboration among blood service organizations in order to save people's lives. Generally, there are 2 major performance measures for blood service operations assessment, which are the shortage and the outdated rates of blood units in the network. Other vital assessment issues are safety and costs. These key performance indexes are essential for outlining the concept of the future research in the blood supply chain area, including risk management. However, there is no evidence of related works that focus on the overall risks of the entire blood supply chain. Thus, this work would propose a study to investigate the risk management in the blood supply chain in order to evaluate the management actions for risk mitigation.

\section{Using the house of risk (HOR) model to manage risks in blood supply chain}

Pujawan and Geraldin [57] have proposed the house of risk (HOR) framework which was modeled based on the SCRM context. They incorporated the concepts of Failure Mode Effects Analysis (FMEA) and House of Quality (HOQ) to propose the HOR model in order to investigate the occurrence of risk agents which could trigger the potential risk events as well as the evaluation of proactive actions. This study initially stated that one risk agent could possibly trigger more than one risk events based on the FMEA concept. Therefore, the model will be used to evaluate the risk events and the related risk agents separately. Moreover, it is necessary to assign the relationship between each risk agent and the related risk events that are corresponding to that agent in order to calculate the aggregate risk potential of a risk agent (ARP). ARP is generally used to rank the risk agents according to their significant level, and the HOQ concept is applied to prioritize the preventive actions based on the value of ARP of each risk agent.

The HOR framework consists of 2 functional models for risk assessment and risk mitigation planning. The prioritized risk agents are determined using HOR1 model, and HOR2 model is used to prioritize the preventive actions in order to handle that risk agent. The HOR1 is carried out to identify any potential risk events in each process and conduct severity assessment along with identifying risk agents and measuring their likelihood of occurrences. Then, the relationship matrix is constructed to define the correlation between each risk event and each risk agent and to calculate the ARPs for ranking risk agents. For the risk evaluation and mitigation planning, the HOR2 is deployed to evaluate the preventive actions and to decide which actions are effective according to the difficulty level of implementation. Risk agents with high rank will be selected to assess the preventive actions in order to mitigate one or more possible risk agents. The relationship between each action and risk agent is assigned to compute the total effectiveness of each action. The degree of implementation difficulty is assessed to calculate the total effectiveness to difficulty ratio in order to prioritize each mitigation action. The action with high rank will be selected as an effective risk mitigation plan for a proactive risk management. The framework of HOR 1 and HOR2 models is presented in Figure 3. 


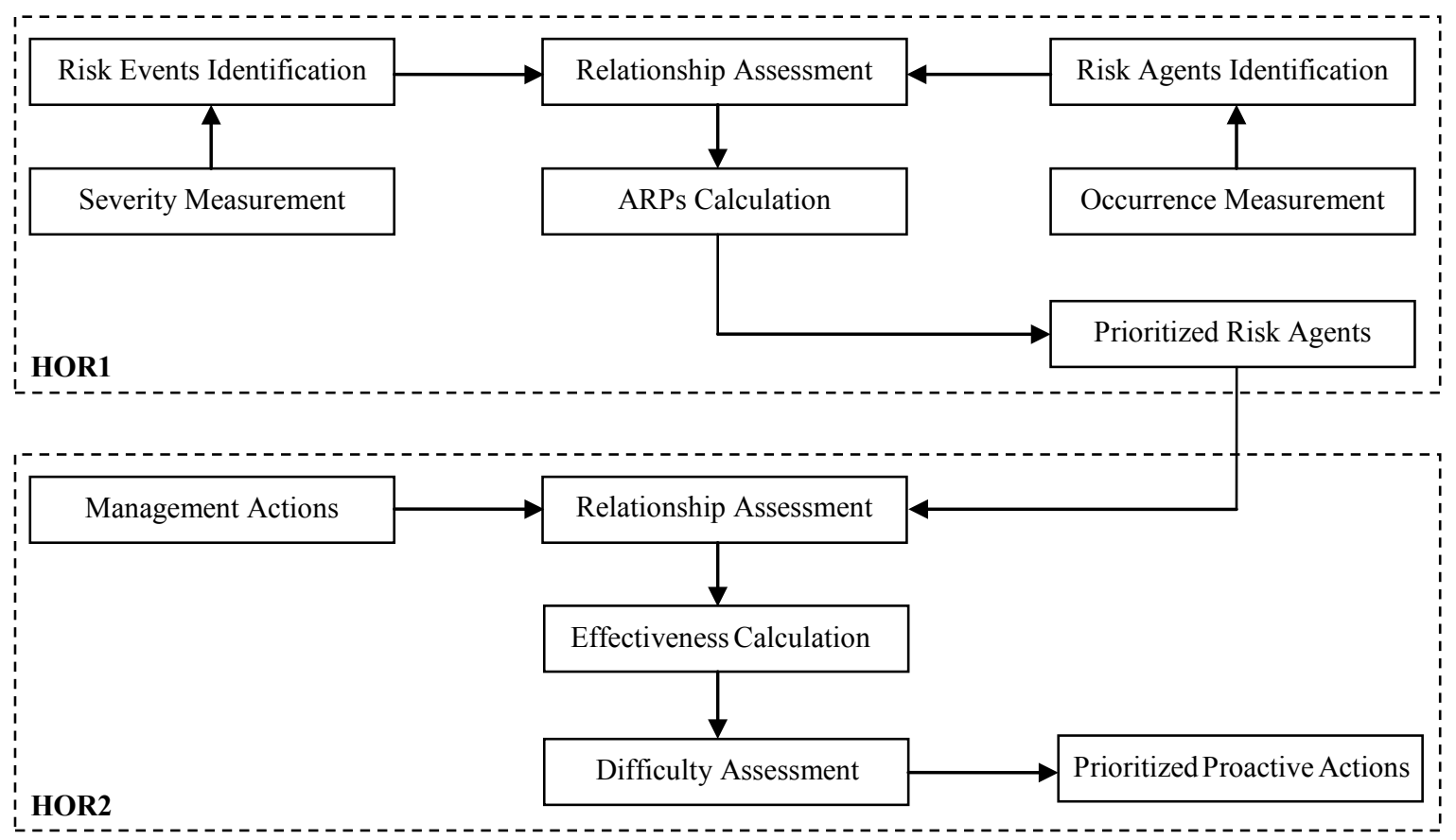

Figure 3 House of risk framework.

The HOR framework is a useful risk management tool which can be applied in practice with the calculation using a simple spreadsheet application. Several analytical methods can be integrated into the HOR model for making the identification of risk events and associated risk agents as well as the evaluation of proactive actions more quantifiable. For example, the HOR model has been used for managing risks in lean implementation in a manufacturing company [58] and a new food product development [59]. The HOR framework has also been applied in the SCRM of frozen shrimp [60] and furniture [61] supply chains. The HOR framework is a proactive model which is used to identify potential risk events, assess the probability of occurrence of risk agents, and analyze the relationship of each risk event and agent in the supply chains. The model is able to evaluate the preventive actions based on the effectiveness and the difficulty to implement each action. Thus, it will be advantageous in terms of times and costs, and practical to apply the HOR framework in order to conduct the risk management in the blood supply chain. The results could further support the practitioners in blood service organizations to assess the potential risks and to determine the preventive actions in the context.

\section{Study settings}

This research was conducted in the largest province of Thailand in which the Regional Blood Center 5 is located. This RBC is a single center model that serves more than $60 \mathrm{HBBs}$ in 4 provinces. The RBC operates blood collection, blood processing, and blood production as well as blood inventory management to serve the needs of all HBBs in the network. When there are requests from the HBBs, the RBC has the responsibility to distribute blood products to them. Thus, it is vital for the $\mathrm{RBC}$ to control and monitor its blood inventory in the blood center. Each HBB has to work closely with the RBC in order to share the essential blood demand information and manage patient blood demand fulfillment appropriately.

This work applied SCRM as a research method to study risk management in the blood supply chain. Typically, RMP consists of risk identification, risk measurement, risk assessment, risk evaluation, and risk mitigation planning. However, several qualitative and quantitative-based methods have been proposed to manage more than one risk in the supply chain. Initially, for the risk identification, we 
http://wjst.wu.ac.th

reviewed literature together with the functions of the RBC and the HBBs to study their fundamental characteristics and processes in order to examine the outcomes of incorporating proactive risk management in the blood supply chain. Opinions of experts and practitioners in the real context have been sought to elaborate on what can go wrong and how to response to any wrong actions or decisions so that the framework of this study could be outlined properly. The preliminary study has identified that demand and supply uncertainties together with blood shortage and outdated issues are the key risk factors in delivering blood services. To measure and assess the risk, we applied integrated quantitative methods, the FMEA and the QFD, of the HOR model to explore risks in the blood supply chain. The HOR1 is used to assess the risks in the blood service operations. The HOR2 is applied to evaluate such risks and then find out the proactive ways to handle these risks. Furthermore, process to manage the whole blood supply chain has been proposed to conceptualize the blood service operations. However, in this study risks are assessed not only in terms of safety and quality, but risks in the entire blood service operations are also evaluated. The research framework is shown in Figure 4.

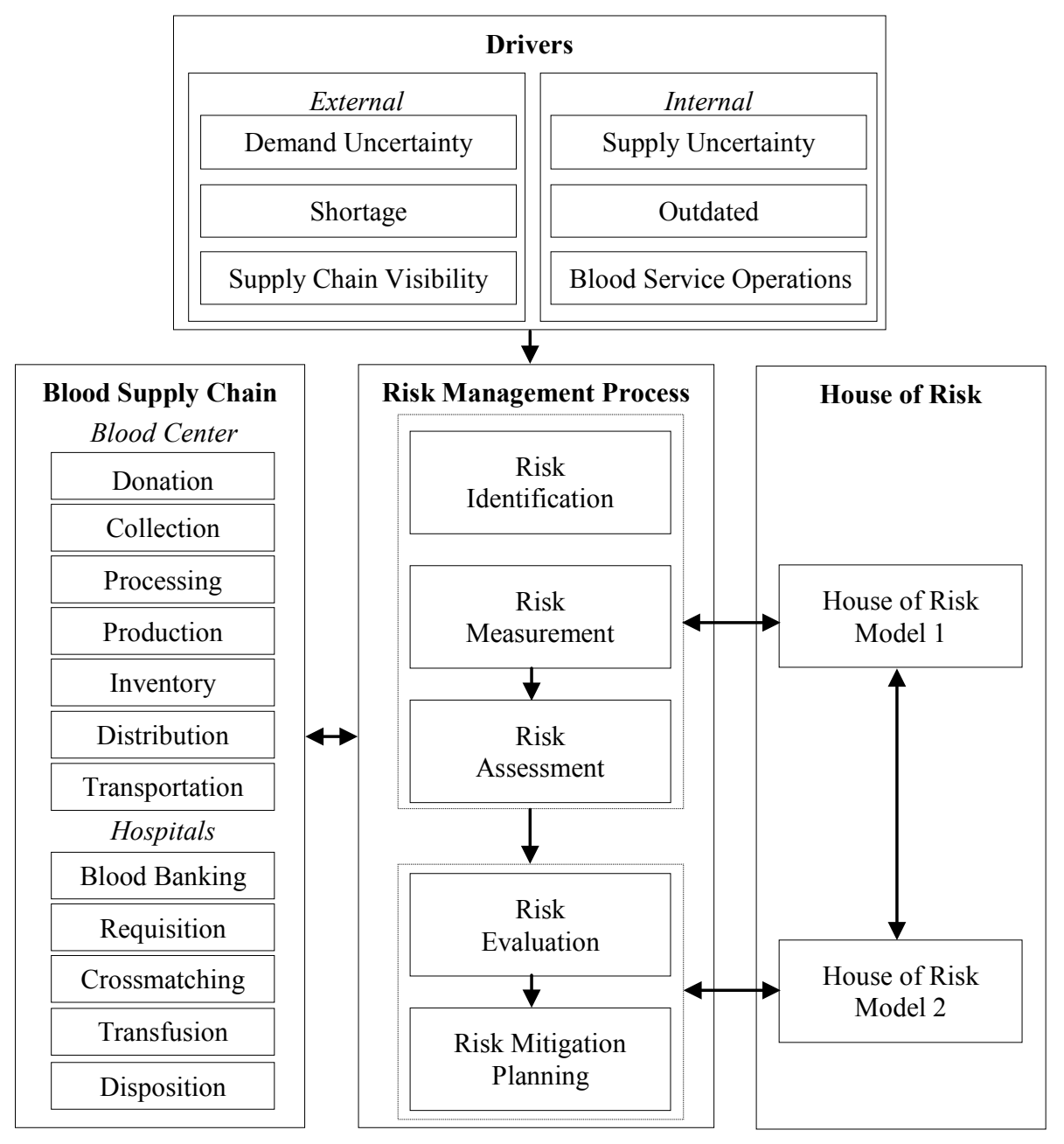

Figure 4 Research framework. 
http://wjst.wu.ac.th

\section{Results and discussion}

Risk event identification and assessment

Risk events are identified in the blood supply chain management based on document reviews and panel discussions with the experts and the practitioners in the field. We provided a guideline on identifying "what the potential risk is in each process" and brainstormed to unravel "what can go wrong" in managing blood operations for future risk event identification and assessment. There are 30 risk events identified throughout deep interview and brainstorming with the participants. In the RBC, there are 19 risk events identified in blood supply chain processes, 7 of which are associated with collection, 3 with blood processing, 4 with storage, 2 with distribution, and 3 with transportation. In the HBBs, there are 7 risk events associated with blood banking management, 3 with requisition, and one with transfusion.

A modified Delphi technique was applied to obtain the severity assessment of each risk event. We held the meeting to collect the risk events' severity assessment from 10 well-experienced participants. The participants consisted of the head directors, the mid-level practitioners, and the experienced staff from the RBC and the HBBS, and the other healthcare supply chain experts. During the meeting, assessment data were collected repeatedly using questionnaires for the participants. Then, feedbacks were offered to the participants for their verifications. The severity values of the risk events, varying from 1 to 10 [62], indicate the impact of each risk. A value of 1 shows almost no risk effect while a value of 10 indicates an imminent risk impact to the blood supply chain. The entire identified risk events and the severity assessments in this study are presented in Table $\mathbf{1 .}$

Table 1 Identified risk events and severity assessment in the blood supply chain management.

\begin{tabular}{|c|c|c|c|c|}
\hline Main process & Activity & Risk event & Severity & Code \\
\hline \multicolumn{5}{|l|}{ Blood Collection } \\
\hline & \multirow[t]{2}{*}{ Demand Management } & Demand collection planning error & 8 & $\mathrm{E}_{1}$ \\
\hline & & Inadequate collection & 10 & $\mathrm{E}_{2}$ \\
\hline & \multirow[t]{2}{*}{ Donor Management } & Inaccessible promotion of blood donation & 8 & $\mathrm{E}_{3}$ \\
\hline & & Discontinuous monitoring of blood donors & 6 & $\mathrm{E}_{4}$ \\
\hline & \multirow{3}{*}{$\begin{array}{l}\text { Donor Screening } \\
\text { Blood Collection }\end{array}$} & Failure donor screening & 8 & $\mathrm{E}_{5}$ \\
\hline & & Quality and safety during blood donation & 8 & $\mathrm{E}_{6}$ \\
\hline & & $\begin{array}{l}\text { Standardization of blood collection in } \\
\text { donation }\end{array}$ & 8 & $\mathrm{E}_{7}$ \\
\hline \multicolumn{5}{|l|}{ Blood Processing } \\
\hline & Processing & Blood product production forecasting error & 5 & $\mathrm{E}_{8}$ \\
\hline & Testing & Lack of blood infection test kit & 8 & $\mathrm{E}_{9}$ \\
\hline & Disposal & Safety disposition of positive units & 9 & $\mathrm{E}_{10}$ \\
\hline \multicolumn{5}{|l|}{ Blood Storage } \\
\hline & \multirow[t]{3}{*}{ Inventory Management } & Inappropriate blood inventory level & 8 & $\mathrm{E}_{11}$ \\
\hline & & Insufficient demand responding to hospitals & 10 & $\mathrm{E}_{12}$ \\
\hline & & Shortage of emergency stock units & 10 & $\mathrm{E}_{13}$ \\
\hline & Disposal & Safety disposition of expired units & 5 & $\mathrm{E}_{14}$ \\
\hline \multicolumn{5}{|l|}{ Blood Distribution } \\
\hline & Issuing & Improper blood issuing (age) & 7 & $\mathrm{E}_{15}$ \\
\hline & Allocation & Improper blood allocation (units) & 8 & $\mathrm{E}_{16}$ \\
\hline \multicolumn{5}{|l|}{ Blood Transportation } \\
\hline & Quality Control & Unstandardized blood packing in delivery & 8 & $\mathrm{E}_{17}$ \\
\hline & Transportation & Unstandardized blood transportation vehicle & 8 & $\mathrm{E}_{18}$ \\
\hline & & Delay in transportation & 8 & $\mathrm{E}_{19}$ \\
\hline
\end{tabular}


http://wjst.wu.ac.th

\begin{tabular}{|c|c|c|c|c|}
\hline Main process & Activity & Risk event & Severity & Code \\
\hline \multicolumn{5}{|l|}{ Blood Banking } \\
\hline & Demand Management & Patients' demand planning error & 8 & $\mathrm{E}_{20}$ \\
\hline & \multirow[t]{2}{*}{ Blood Requisition } & Inadequate blood allocated & 9 & $\mathrm{E}_{21}$ \\
\hline & & Delay in blood allocated & 7 & $\mathrm{E}_{22}$ \\
\hline & \multirow[t]{3}{*}{ Blood Bank Management } & Blood shortage & 10 & $\mathrm{E}_{23}$ \\
\hline & & Queuing error in blood reservation from & 5 & $\mathrm{E}_{24}$ \\
\hline & & Inappropriate blood inventory level & $\begin{array}{l}5 \\
5\end{array}$ & $\mathrm{E}_{25}$ \\
\hline & Disposal & Safety of expired units disposition & 5 & $\mathrm{E}_{26}$ \\
\hline \multicolumn{5}{|l|}{ Brood Requisition } \\
\hline & Requisition & Exceeding blood requisition in actual usage & 6 & $\mathrm{E}_{27}$ \\
\hline & Crossmatching & Urgency of blood compatibility testing & 7 & $\mathrm{E}_{28}$ \\
\hline & Inventory Management & Outdated of unused blood & 8 & $\mathrm{E}_{29}$ \\
\hline \multicolumn{5}{|l|}{ Blood Transfusion } \\
\hline & Safety Control & Blood transfusion reaction & 9 & $\mathrm{E}_{30}$ \\
\hline
\end{tabular}

Identification of risk agents and evaluation of their occurrences

In this stage, we provide a summarized knowledge of the supply chain risks and uncertainties from the literature in order to suggest the participants how to identify the risk agents using relevant historical data and documents. The risk agents identified in the discussion consist of 16 issues as shown in Table 2. The probability of each occurrence is evaluated for each risk agent by the participants using the same criteria as in the previous step. The assessing scale varying from 1 to 10 is used to evaluate the probability of each occurrence, where 1 represents an event that almost never occurs and 10 means an event that is almost certain to happen.

Table 2 Identified risk agents and probability of occurrence values in blood supply chain management.

\begin{tabular}{lcc}
\hline Risk agent & Occurrence & Code \\
\hline Delays in allocation and distribution & 5 & $\mathrm{~A}_{1}$ \\
Disruptions in logistics processes & 3 & $\mathrm{~A}_{2}$ \\
Unstandardized packaging in delivery and transportation & 5 & $\mathrm{~A}_{3}$ \\
Complexities in inventory processes & 8 & $\mathrm{~A}_{4}$ \\
Exceeding blood requisition in actual usage & 8 & $\mathrm{~A}_{5}$ \\
Delay in blood cost payment & 7 & $\mathrm{~A}_{6}$ \\
Improper blood demand analysis & 6 & $\mathrm{~A}_{7}$ \\
Insufficient information for decision-making & 10 & $\mathrm{~A}_{8}$ \\
Lack of trust & 8 & $\mathrm{~A}_{9}$ \\
Lack of collaboration & 9 & $\mathrm{~A}_{l 0}$ \\
Problems in quality control & 6 & $\mathrm{~A}_{l 1}$ \\
Insufficient capacity & 6 & $\mathrm{~A}_{l 2}$ \\
Inexperienced staff & 3 & $\mathrm{~A}_{l 3}$ \\
Problems in safety issue & 5 & $\mathrm{~A}_{I 4}$ \\
Limited information sharing & 8 & $\mathrm{~A}_{l 5}$ \\
Uncertainties in demand and supply & 10 & $\mathrm{~A}_{l 6}$ \\
\hline
\end{tabular}


http://wjst.wu.ac.th

\section{Evaluation of relationships between risk agents and risk events}

Generally, the relationship matrix of the House of Quality method is constructed to evaluate correlations between customer's requirements and performance measures in a product/service development. It has been used widely in manufacturers and services development such as electronics, home appliances, construction equipment, and agricultural engines as well as swimming schools and retail stores [63]. The correlation values are assigned by respective indexes such as 9-3-1, 4-2-1, or 5-3-1 where zero represents no correlation between each pair. In the HOR1 model, the relationship between each risk agent and each risk event $\left(\mathrm{R}_{i j}\right)$ is evaluated with a single value of $0,1,3$, or 9 , where 0 represents no correlation and 1,3, and 9 represent low, moderate, and high correlations, respectively. For example in Table 3, $\mathrm{A}_{7}$ has high correlation value of 9 on $\mathrm{E}_{1}, \mathrm{E}_{8}$, and $\mathrm{E}_{11}$, indicating that improper blood demand analysis would definitely affect the inaccuracy of demand collection planning, blood product production forecasting, and blood inventory level, respectively. In contrast, $\mathrm{A}_{4}$ has no relationship with $\mathrm{E}_{30}$, suggesting that complexities in inventory processes do not result in any blood transfusion reaction to the patient.

The correlation value between each risk agent and each risk event is used to calculate aggregate risk potential score for risk agent $j\left(\mathrm{ARP}_{j}\right)$. The higher the $\mathrm{ARP}_{j}$ value, the more impact that risk agent $j$ is. The risk agents with high $\mathrm{ARP}_{j}$ values will be selected for risk preventive and mitigation measures. $\mathrm{ARP}_{j}$ score is obtained by multiplying the probability of occurrence of risk agent $j\left(\mathrm{O}_{j}\right)$ with the summation of the product of each severity of risk event $i\left(\mathrm{~S}_{i}\right)$ and the correlation value between risk agent $j$ and risk event $i\left(\mathrm{R}_{i j}\right)$ as shown in Eq. (1).

$\mathrm{ARP}_{j}=O_{j} \sum_{i} S_{i} R_{i j}$

The HOR 1 model is presented in Table 3. The risk events $\left(\mathrm{E}_{i}\right)$ are in the far left column, the severity values of each risk event $\left(\mathrm{S}_{i}\right)$ are in the far right column, and the correlation values between each risk agent $j$ and each risk event $i$ are also shown in the matrix. For example, $\mathrm{ARP}_{10}$, which is aggregate risk potential score for risk agent 10, is calculated by multiplying the probability of occurrence of risk agent 10 to the summation of the product of corresponding correlation values and severity of associated risk events. $\mathrm{ARP}_{10}$ is calculated as shown in the following formula;

$\mathrm{ARP}_{10}=9 \times[9(10+10+7+8+8+9+10)+3(8+8+6+5+8+10+5+5+7+8)+1(8+8+8+8+8+7+6+9)]=7,272$

Risk agent 10 has the $\mathrm{ARP}_{10}$ value of 7,272, which is the highest $\mathrm{ARP}_{j}$ value and rank $k$ of $\mathrm{P}_{10}$ is assigned value equal to 1 . Each $\mathrm{ARP}_{j}$ is ranked in ascending order according to the descending values of $\mathrm{ARP}_{j}$ 's. The results in Table 3 show that lack of collaboration $\left(\mathrm{A}_{10}\right)$, insufficient information for decisionmaking $\left(\mathrm{A}_{8}\right)$, and limited information sharing $\left(\mathrm{A}_{16}\right)$ are the top 3 risk agents that have significant impacts on blood supply chain management. Surprisingly, delay in blood cost payment $\left(\mathrm{A}_{6}\right)$ does not have or has minimal impact on the blood service operations. 
http://wjst.wu.ac.th

Table 3 HOR1 results of the blood supply chain risk management.

\begin{tabular}{|c|c|c|c|c|c|c|c|c|c|c|c|c|c|c|c|c|c|}
\hline \multirow{2}{*}{$\begin{array}{l}\text { Risk } \\
\text { event }\end{array}$} & \multicolumn{16}{|c|}{ Risk agent } & \multirow{2}{*}{$\mathbf{S}_{i}$} \\
\hline & $\mathbf{A}_{1}$ & $\mathbf{A}_{2}$ & $\mathbf{A}_{3}$ & $\mathbf{A}_{4}$ & $\mathbf{A}_{5}$ & $\mathbf{A}_{6}$ & $\mathbf{A}_{7}$ & $\mathbf{A}_{\boldsymbol{\delta}}$ & $\mathbf{A}_{9}$ & $\mathbf{A}_{10}$ & $\mathbf{A}_{11}$ & $\mathbf{A}_{12}$ & $\mathbf{A}_{13}$ & $\mathbf{A}_{14}$ & $\mathbf{A}_{15}$ & $\mathbf{A}_{16}$ & \\
\hline $\mathrm{E}_{1}$ & 3 & 1 & 0 & 3 & 3 & 0 & 9 & 9 & 1 & 3 & 0 & 0 & 3 & 0 & 9 & 9 & 8 \\
\hline $\mathrm{E}_{2}$ & 3 & 3 & 0 & 9 & 3 & 1 & 9 & 3 & 3 & 9 & 0 & 1 & 0 & 0 & 3 & 9 & 10 \\
\hline $\mathrm{E}_{3}$ & 0 & 1 & 0 & 1 & 0 & 0 & 3 & 3 & 3 & 3 & 0 & 0 & 1 & 0 & 3 & 0 & 8 \\
\hline $\mathrm{E}_{4}$ & 0 & 0 & 0 & 3 & 0 & 0 & 3 & 3 & 3 & 3 & 0 & 0 & 1 & 0 & 3 & 0 & 6 \\
\hline $\mathrm{E}_{5}$ & 0 & 0 & 0 & 1 & 0 & 0 & 0 & 1 & 9 & 1 & 9 & 1 & 9 & 9 & 1 & 0 & 8 \\
\hline $\mathrm{E}_{6}$ & 0 & 3 & 3 & 1 & 0 & 0 & 0 & 0 & 1 & 0 & 9 & 1 & 1 & 9 & 0 & 0 & 8 \\
\hline $\mathrm{E}_{7}$ & 1 & 9 & 9 & 1 & 0 & 0 & 0 & 0 & 1 & 0 & 9 & 3 & 3 & 9 & 0 & 0 & 8 \\
\hline $\mathrm{E}_{8}$ & 3 & 0 & 0 & 3 & 9 & 0 & 9 & 3 & 1 & 3 & 0 & 0 & 3 & 0 & 3 & 3 & 5 \\
\hline $\mathrm{E}_{9}$ & 0 & 3 & 0 & 1 & 0 & 9 & 0 & 1 & 3 & 1 & 1 & 3 & 0 & 0 & 0 & 0 & 8 \\
\hline $\mathrm{E}_{10}$ & 0 & 1 & 0 & 0 & 0 & 0 & 0 & 0 & 0 & 0 & 9 & 1 & 3 & 9 & 0 & 0 & 9 \\
\hline $\mathrm{E}_{11}$ & 9 & 1 & 0 & 3 & 3 & 0 & 9 & 9 & 1 & 3 & 0 & 0 & 3 & 0 & 9 & 3 & 8 \\
\hline $\mathrm{E}_{12}$ & 3 & 3 & 3 & 9 & 9 & 0 & 3 & 3 & 1 & 9 & 0 & 0 & 3 & 0 & 9 & 9 & 10 \\
\hline $\mathrm{E}_{13}$ & 3 & 3 & 3 & 3 & 9 & 0 & 3 & 3 & 1 & 3 & 0 & 0 & 1 & 0 & 1 & 3 & 10 \\
\hline $\mathrm{E}_{14}$ & 0 & 1 & 0 & 0 & 0 & 0 & 1 & 0 & 0 & 0 & 3 & 1 & 1 & 9 & 0 & 0 & 5 \\
\hline $\mathrm{E}_{15}$ & 3 & 1 & 0 & 9 & 3 & 0 & 3 & 9 & 1 & 9 & 0 & 0 & 9 & 0 & 3 & 3 & 7 \\
\hline $\mathrm{E}_{16}$ & 3 & 1 & 0 & 3 & 9 & 0 & 9 & 9 & 3 & 9 & 0 & 0 & 9 & 0 & 3 & 3 & 8 \\
\hline $\mathrm{E}_{17}$ & 3 & 3 & 9 & 1 & 0 & 1 & 0 & 0 & 3 & 1 & 9 & 3 & 3 & 3 & 1 & 0 & 8 \\
\hline $\mathrm{E}_{18}$ & 9 & 3 & 9 & 0 & 0 & 0 & 0 & 0 & 3 & 1 & 9 & 3 & 1 & 3 & 1 & 0 & 8 \\
\hline $\mathrm{E}_{19}$ & 9 & 9 & 9 & 0 & 0 & 0 & 0 & 1 & 3 & 1 & 1 & 0 & 3 & 3 & 1 & 0 & 8 \\
\hline $\mathrm{E}_{20}$ & 9 & 1 & 0 & 9 & 3 & 0 & 9 & 9 & 1 & 9 & 0 & 0 & 9 & 0 & 9 & 9 & 8 \\
\hline $\mathrm{E}_{21}$ & 3 & 3 & 9 & 3 & 3 & 0 & 3 & 3 & 3 & 9 & 0 & 1 & 3 & 0 & 3 & 3 & 9 \\
\hline $\mathrm{E}_{22}$ & 9 & 9 & 9 & 3 & 1 & 1 & 0 & 1 & 1 & 1 & 0 & 1 & 1 & 0 & 0 & 0 & 7 \\
\hline $\mathrm{E}_{23}$ & 9 & 3 & 1 & 9 & 3 & 1 & 9 & 3 & 3 & 9 & 0 & 3 & 3 & 0 & 0 & 9 & 10 \\
\hline $\mathrm{E}_{24}$ & 3 & 1 & 0 & 3 & 9 & 0 & 1 & 3 & 1 & 3 & 0 & 0 & 3 & 0 & 3 & 1 & 5 \\
\hline $\mathrm{E}_{25}$ & 1 & 1 & 0 & 3 & 3 & 0 & 3 & 3 & 1 & 3 & 0 & 0 & 3 & 0 & 3 & 3 & 5 \\
\hline $\mathrm{E}_{26}$ & 0 & 0 & 0 & 0 & 0 & 0 & 0 & 0 & 0 & 0 & 9 & 1 & 1 & 9 & 0 & 0 & 5 \\
\hline $\mathrm{E}_{27}$ & 0 & 9 & 0 & 3 & 9 & 0 & 3 & 3 & 3 & 1 & 0 & 0 & 3 & 0 & 0 & 1 & 6 \\
\hline $\mathrm{E}_{28}$ & 0 & 9 & 0 & 3 & 3 & 0 & 1 & 3 & 1 & 3 & 0 & 3 & 3 & 9 & 0 & 3 & 7 \\
\hline $\mathrm{E}_{29}$ & 0 & 3 & 0 & 9 & 3 & 0 & 3 & 0 & 0 & 3 & 0 & 1 & 1 & 9 & 0 & 1 & 8 \\
\hline $\mathrm{E}_{30}$ & 0 & 3 & 0 & 0 & 0 & 0 & 0 & 0 & 1 & 1 & 1 & 0 & 3 & 9 & 0 & 0 & 9 \\
\hline $\mathbf{O}_{j}$ & 5 & 3 & 5 & 5 & 8 & 7 & 6 & 10 & 8 & 9 & 6 & 6 & 3 & 5 & 8 & 10 & \\
\hline $\mathbf{A R P}_{j}$ & 3,470 & 2,067 & 2,560 & 3,840 & 5,440 & 728 & 4,464 & 6,800 & 3,584 & 7,272 & 3,312 & 1,296 & 2,160 & 3,600 & 4,352 & 5,760 & \\
\hline $\mathbf{P}_{j}$ & 10 & 14 & 12 & 7 & 4 & 16 & 5 & 2 & 9 & 1 & 11 & 15 & 13 & 8 & 6 & 3 & \\
\hline
\end{tabular}

Risk evaluation and mitigation planning

The Pareto analysis was conducted as a diagram as shown in Figure $\mathbf{5}$ using $\mathrm{ARP}_{j}$ scores to elucidate the risk agents that contribute to remarkable impact on the blood supply chain. The results can be interpreted that there are 7 significant risk agents which contribute to approximately 65 percent of the total $\mathrm{ARP}_{j}$ value. These 7 risk agents are lack of collaboration $\left(\mathrm{A}_{10}\right)$, insufficient information for decisionmaking $\left(\mathrm{A}_{8}\right)$, uncertainties in demand and supply $\left(\mathrm{A}_{16}\right)$, exceeding blood requisition in actual usage $\left(\mathrm{A}_{5}\right)$, improper blood demand analysis $\left(\mathrm{A}_{7}\right)$, limited information sharing $\left(\mathrm{A}_{15}\right)$, and complexities in inventory $\left(\mathrm{A}_{4}\right)$, respectively. 
http://wjst.wu.ac.th

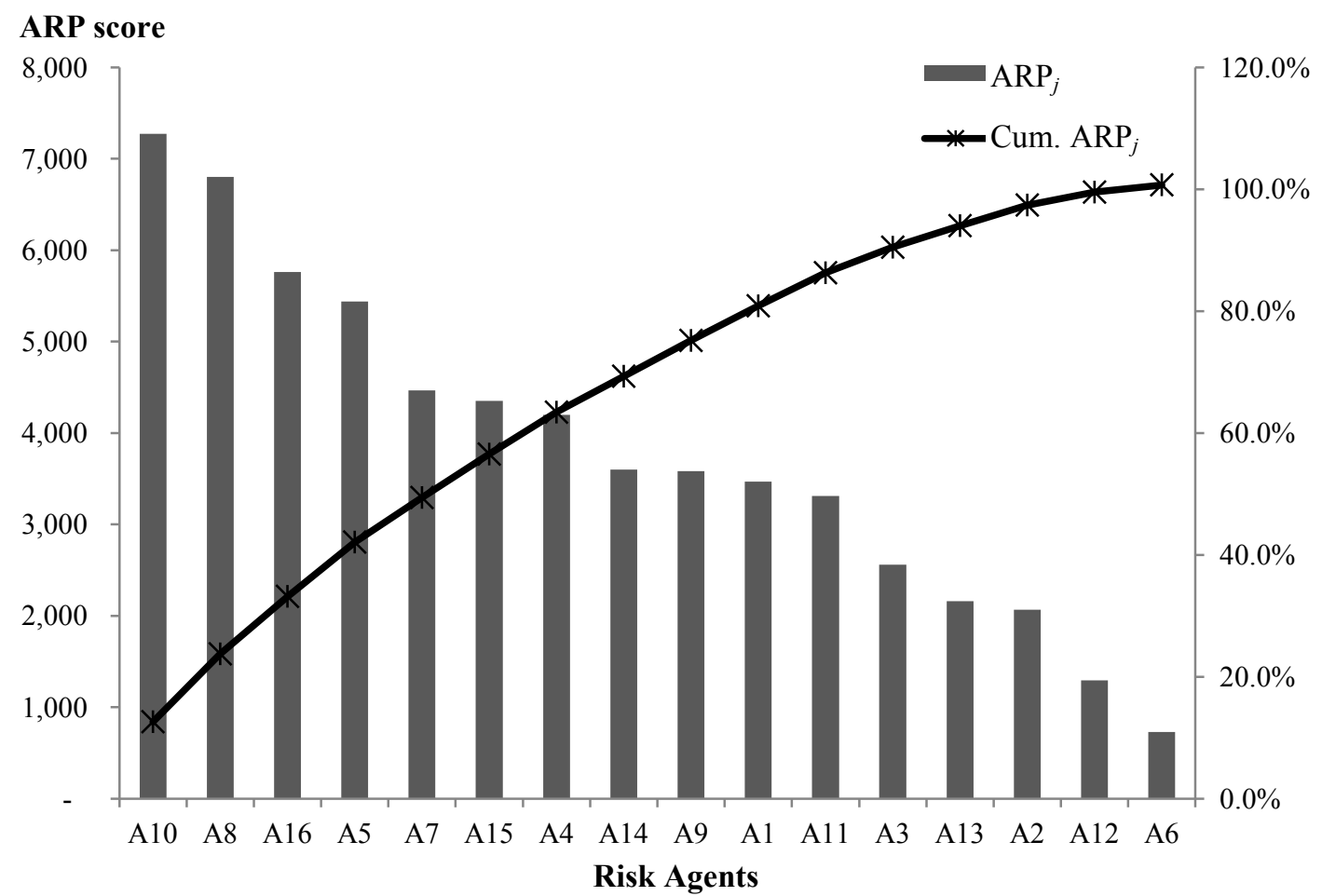

Figure 5 Pareto diagram of ARP scores for all risk agents.

The HOR2 model is used to identify and prioritize appropriate management actions for the blood service organizations using the values of total effectiveness of proactive action $\left(\mathrm{TE}_{k}\right)$ and the difficulty degree of each action $\left(\mathrm{D}_{k}\right)$. Eight preventive and mitigation actions are proposed from brainstorming discussion with relevant participants to lessen these remarkable risk agents. These actions are supply chain visibility $\left(\mathrm{MA}_{1}\right)$, tracking and traceability $\left(\mathrm{MA}_{2}\right)$, information sharing $\left(\mathrm{MA}_{3}\right)$, enhancing the collaboration $\left(\mathrm{MA}_{4}\right)$, demand and supply statistical analysis $\left(\mathrm{MA}_{5}\right)$, audit planning in network $\left(\mathrm{MA}_{6}\right)$, online data system in network $\left(\mathrm{MA}_{7}\right)$, and actual demand planning $\left(\mathrm{MA}_{8}\right)$.

Each management action can be implemented to mitigate more than one risk agents. The relationships between each management action and each risk agent $\left(\mathrm{E}_{j k}\right)$ is assigned a single value of 0,1 , 3 , or 9 , representing no correlation, low, moderate, and high correlations, respectively. The total effectiveness of each action $k\left(\mathrm{TE}_{k}\right)$ is calculated to obtain a score of the effectiveness of each management action, where $\mathrm{E}_{j k}$ represents the correlation value between risk agent $j$ and risk action $k . \mathrm{TE}_{k}$ is computed as shown in Eq. (2).

$\mathrm{TE}_{k}=\sum_{j} \mathrm{ARP}_{j} \mathrm{E}_{j k} \quad \forall k$

The $\mathrm{TE}_{k}$ scores are used to arrange each management action $k$ in descending order based on their effectiveness values. In reality, appropriate actions are neither cost-effective nor efficient resource utilization options. Hence, it is important to evaluate the ease of action implementation factor. This factor is defined as difficulty degree of each action $\left(\mathrm{D}_{k}\right)$. This degree reflects the complications to implement each risk management action in blood supply chain management such as time, resource, cost, technology, and so on. The $\mathrm{D}_{k}$ is classified into 3 levels, consisting of low, medium, and high with the scores of 3, 4, and 5 , respectively. The total effectiveness of proactive action $\left(\mathrm{TE}_{k}\right)$ and difficulty degree of each action $\left(\mathrm{D}_{k}\right)$ are gathered from the participants' opinion in order to quantify the total effectiveness to difficulty 
http://wjst.wu.ac.th

ratio $\left(\mathrm{ETD}_{k}\right)$, calculated by $\mathrm{ETD}_{k}=\mathrm{TE}_{k} / \mathrm{D}_{k}$. Finally, each management action is assigned the rank $\left(\mathrm{R}_{k}\right)$ in a descending order by their $\mathrm{ETD}_{k}$ scores to prioritize the proactive actions. The actions with the higher $\mathrm{ETD}_{k}$ scores are the recommended approach for managing risks in blood supply chain management.

The HOR2 results are presented in Table 4. The risk agents are in the left column, the $\mathrm{ARP}_{j}$ scores are in the right column, the management actions are listed in the top row, and the correlation values between each action and each risk agent are evaluated in the matrix. According to the HOR2 results, $\mathrm{MA}_{4}$ has high correlation on $\mathrm{A}_{10}, \mathrm{~A}_{8}, \mathrm{~A}_{5}$, and $\mathrm{A}_{15}$, which points out that enhancing the collaboration could reduce the likelihood of occurrence of lack of collaboration $\left(\mathrm{A}_{10}\right)$, insufficient information for decisionmaking $\left(\mathrm{A}_{8}\right)$, exceeding blood requisition in actual usage $\left(\mathrm{A}_{5}\right)$, and limited information sharing $\left(\mathrm{A}_{15}\right)$. On the contrary, $\mathrm{MA}_{6}$ has no correlation on $\mathrm{A}_{16}$, meaning that audit planning in network does not relate to the uncertainties in demand and supply. Thus, enhancing the collaboration $\left(\mathrm{MA}_{4}\right)$ is first prioritized with $\mathrm{R}_{I}=$ 1 , which is the most proactive action for managing risks in the blood supply chain management. Information sharing $\left(\mathrm{MA}_{3}\right)$ and demand and supply statistical analysis $\left(\mathrm{MA}_{5}\right)$ are arranged in the second and the third ranks, respectively, while tracking and traceability $\left(\mathrm{MA}_{2}\right)$ seems to be a less effective and more difficult action to implement for risk management in the blood service operations.

Table 4 HOR2 results of the blood supply chain risk management.

\begin{tabular}{|c|c|c|c|c|c|c|c|c|c|c|}
\hline \multirow{2}{*}{\multicolumn{2}{|c|}{ Risk agent }} & \multicolumn{8}{|c|}{ Management Actions } & \multirow{3}{*}{$\mathbf{A R P}$} \\
\hline & & 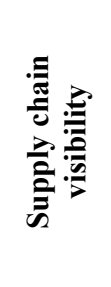 & 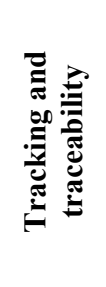 & 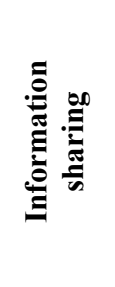 & 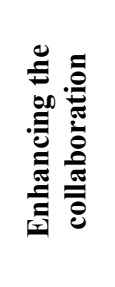 & 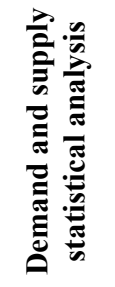 & 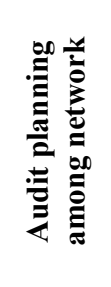 & 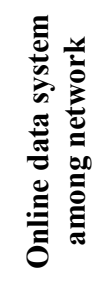 & 总 & \\
\hline Code & Details & $\mathbf{M A}_{1}$ & $\mathbf{M A}_{2}$ & $\mathbf{M A}_{3}$ & $\mathbf{M A}_{4}$ & $\mathbf{M A}_{5}$ & $\mathbf{M A}_{6}$ & $\mathbf{M A}_{7}$ & $\mathbf{M A}_{8}$ & \\
\hline $\mathrm{A}_{10}$ & Lack of collaboration & 9 & 3 & 9 & 9 & 3 & 9 & 9 & 1 & 7,272 \\
\hline $\mathrm{A}_{8}$ & Insufficient information for decision-making & 9 & 3 & 9 & 9 & 3 & 3 & 9 & 3 & 6,800 \\
\hline $\mathrm{A}_{16}$ & Uncertainties in demand and supply & 1 & 1 & 3 & 3 & 9 & 0 & 1 & 3 & 5,760 \\
\hline $\mathrm{A}_{5}$ & Exceeding requisition in actual usage & 3 & 1 & 9 & 9 & 9 & 1 & 9 & 9 & 5,440 \\
\hline $\mathrm{A}_{7}$ & Improper blood demand analysis & 3 & 0 & 9 & 3 & 9 & 1 & 9 & 9 & 4,464 \\
\hline $\mathrm{A}_{15}$ & Limited information sharing & 9 & 1 & 9 & 9 & 3 & 9 & 9 & 0 & 4,352 \\
\hline $\mathrm{A}_{4}$ & Complexities in inventory processes & 3 & 3 & 3 & 3 & 0 & 1 & 1 & 1 & 4,200 \\
\hline \multicolumn{2}{|c|}{ Total effectiveness of each action $\left(\mathrm{TE}_{k}\right)$} & 213,888 & 70,368 & 284,832 & 258,048 & 196,248 & 139,120 & 264,912 & 138,288 & \\
\hline \multicolumn{2}{|r|}{ Difficulty degree of each implementation $\left(\mathrm{D}_{k}\right)$} & $\mathrm{H}(5)$ & $\mathrm{H}(5)$ & $\mathrm{M}(4)$ & $\mathrm{L}(3)$ & $\mathrm{L}(3)$ & $\mathrm{L}(3)$ & $\mathrm{H}(5)$ & $\mathrm{L}(3)$ & \\
\hline \multicolumn{2}{|c|}{ Effectiveness to difficulty ratio $\left(\mathrm{ETD}_{k}\right)$} & 42,788 & 14,074 & 71,208 & 86,016 & 65,416 & 46,373 & 52,982 & 46,096 & \\
\hline \multicolumn{2}{|c|}{ Rank of priority $\left(\mathrm{R}_{k}\right)$} & 7 & 8 & 2 & 1 & 3 & 5 & 4 & 6 & \\
\hline
\end{tabular}

\section{Discussion}

Risks in blood supply chain management have been investigated by using HOR framework. The advantage of the HOR1 model is an ability to prioritize significant risk agents with high probability of occurrences and trigger associated risk events with high severities in the first step. The triggering concept is also applied in the HOR2 model to evaluate risk management actions in which each action can mitigate more than one risk agents. Finally, these actions are evaluated based on their effectiveness and their difficulty to implement each action. The HOR1 results demonstrate that there are 7 significant risk agents which contribute to approximately 65 percent of the total aggregate risk potential value as shown in Figure 5. However, the underlying results point out that demand management and inventory management processes in both RBC and HBBs are highly affected by these risk agents, especially in uncertainties in demand and supply, insufficient information for decision-making, improper blood demand analysis, 
http://wjst.wu.ac.th

complexities in inventory processes, and lack of collaboration. In demand management processes, the uncertainties will cause the errors not only in patient demand planning in the HBBs but also blood collection planning in the RBC. These consequences probably occur because not only the medical professionals cannot determine the actual needs of blood units for patient's treatments but also the practitioners in Blood Center cannot forecast the amount of the blood collection. It can be concluded from the study that lack of collaboration for patients' demand planning in the HBBs would affect blood collection arrangement in the RBC, which subsequently causes an inadequate blood demand fulfillment in the blood supply chain.

Blood inventory management fundamentally has 3 key measures of performance, which are shortage rate, outdating/wastage rate, and operating costs [64]. According to these key performance measures, the inventory management is a complex task because it involves operating the blood collection, blood production, storage, and distribution from the RBC to respond to the diverse demand in the HBBs. In the RBC, whole blood is collected from donors and it is processed to test for infectious agents as well as determine the blood group. The blood production process is to componentize whole blood into blood products such as red blood cells, platelets, and plasma, whose shelf lives and storage regulations are different. RBC has to define the inventory policies to maintain adequate stock levels in order to ensure sufficient supplies for the HBBs and avoid shortage as well as to lower operating cost. In the HBBs, each blood bank manager is responsible for blood products requisition from the RBC in order to fulfill patients' demand in the hospitals as well as managing blood products inventory to avoid wastage from outdating. Each hospital has a different blood requisition pattern based on its targeted stock level for daily usage and the experience of the blood bank manager. The HBBs have to provide actual demand information in their hospitals to the RBC so that the RBC can manage its blood collection and inventory more effectively. It is strongly recommended that the $\mathrm{RBC}$ and the HBBs have to enhance their collaboration and information sharing in order to minimize miscommunication and risks in the blood supply chain.

The HOR2 model is developed to identify and prioritize management actions to mitigate risks in the blood service organizations. The evaluation of the proposed actions is based on the effectiveness and the difficulty to implement each action. The results of HOR2 are presented in Table 4 . There are 4 management actions which contribute to approximately 65 percent of the total effectiveness to difficulty ratio value. These actions are enhancing the collaboration, information sharing, demand and supply statistical analysis, and online data system among network. It can be concluded that the management actions to mitigate risks in the blood supply chain mainly involve the issues of collaboration between the $\mathrm{RBC}$ and the HBBs. Collaborative Planning, Forecasting, and Replenishment (CPFR) is an information sharing process that aims to increase visibility in a supply chain by cooperative demand planning between stakeholders in the network [65]. The CPFR can be applied to enhance the coordination of the RBC and the HBBs for blood demand forecasting and supply planning in order to manage the uncertainties in the network. The actual blood demand of patient will be analyzed and the results can be used as the input for blood collection planning for the RBC. For example, each HBB can store the blood information (types, groups, units, and usage periods) and use as input data for future blood demand analysis. Moreover, such information can be transmitted to the RBC to use for blood collection planning and blood components production. This could result in reducing blood unit shortage. The information sharing among the network may increase burdens on the storage and analysis, however, the obtained information is useful for reducing difficulty and risks in managing blood inventory. The accuracy of the information achieved is beneficial for the future planning, otherwise, it may produce another risk to the system.

The visibility of demand information will reduce the uncertainty in blood fulfillment process and contribute to the improved blood management throughout the network. However, collaboration aspect has not been mentioned in any literature to use as a tool to improve inventory performance in the blood supply chain. The blood inventory management research in UK suggests that collaboration with other departments within and across the organizations contributes to the enhanced blood utilization in the inventory [66]. The collaborative inventory processes between the RBC and the HBBs should be improved by using real-time data communication tool, such as the web-based system. The online network system allows the blood center and the hospitals to communicate promptly and easily, which is a solution 
http://wjst.wu.ac.th

to mitigate risks and ease complexities in the inventory processes. The management information system (MIS) is a tool to process the data to obtain the rational information in order to support the decision making in the blood service operations. The MIS can be connected between each hospital and the RBC, and used as a mechanism to manage blood inventory more systematically and to better provide the essential information in order to reduce the uncertainties in demand and supply in blood operations management. Practically, the MIS can be used to manage blood demand, blood collection planning, blood components production, blood allocation, and blood inventory. The online system is needed to transmit the accurate and up-to-date information on the sharing network. The ability to track blood stock level and expiration dates could enhance the efficiency of blood inventory and blood allocation management. Moreover, obtaining blood shelf live information would allow the RBC to rotate the nearly expired units to the hospitals in urgent needs. This could reduce the outdated rate in the system.

\section{Conclusions}

This research applied a house of risk (HOR) framework, which is a proactive risk management model to manage risks in the blood supply chain. The entire blood supply chain network consists of blood collection, processing, inventory management, allocation/distribution, and transportation from the blood center to hospital blood banks as well as blood requisition and transfusion within the hospitals. The research framework is proposed to illustrate the cooperation of the practical risk management process and the HOR model which are connected to the blood service operations in the supply chain network. The case study from real situation of blood supply chain risk management is provided to demonstrate the application of the HOR model for managing risk in the healthcare supply chain context.

In the first phase of risk assessment, the HOR1 model was used to identify risk events and risk agents and to assess their severity and likelihood of occurrence values. The correlation matrix was constructed to assign the relationship values between each risk event and each risk agent. The risk agents were prioritized by a calculation of their aggregate risk potential values (ARP) to indicate the significant risks in the blood supply chain management. There are 30 risk events and 16 risk agents identified and assessed in the study. The HOR1 results indicate that lack of collaboration, insufficient information for decision-making, and limited information sharing are the top 3 risk agents that have significant impact on blood supply chain management. On the other hand, delay in blood cost payment does not have nor has minimal impact on the blood service operations. The next phase of risk evaluation and mitigation planning was to evaluate the management actions based on the effectiveness and the difficulty to implement each action using the HOR2 model. The HOR2 results demonstrate that enhancing the collaboration is the most proactive action in order to manage risks in the blood supply chain, followed by information sharing, and demand and supply statistical analysis. The discussion contributes to provide the risk management approaches, which are useful guidelines for practitioners and managers to establish the risk mitigation plan in the blood service organizations.

\section{Acknowledgements}

The authors would like to thank the participants of the Regional Blood Centers and the hospital blood banks in Thailand for the important information support on this research.

\section{References}

[1] K Sethuraman and D Tirupati. Evidence of bullwhip effect in healthcare sector: Causes, consequences and cures. Int. J. Serv. Operat. Manag. 2005; 1, 372-94.

[2] CL Simeone. Business resilience: Reframing healthcare risk management. J. Healthcare Risk Manag. 2015; 35, 31-7.

[3] DA Rangel, TK de Oliveira TK and MS Leite. Supply chain risk classification: Discussion and proposal. Int. J. Prod. Res. 2015; 53, 6868-87. 
http://wjst.wu.ac.th

[4] GR Ledlow, KB Manrodt and DE Scott. The Healthcare Supply Chain. Health care Supply Chain Management: Elements, Operations, and Strategies. Jones \& Bartlett Learning, Burlington, Massachusetts, 2016, p. 1-21.

[5] SMI Ágoston, PC van Mourik and PFW Strengers. Quality risk management: A valuable tool in implementing, maintaining and improving a quality management system. ISBT Sci. Series 2011; 6, 52-5.

[6] A Nagurney, AH Masoumi and M Yu. Supply chain network operations management of a blood banking system with cost and risk minimization. Comput. Manag. Sci. 2012; 9, 205-31.

[7] WP Pierskalla. Supply Chain Management of Blood Banks. Operations Research and Health Care. Springer US, 2005, p. 103-45.

[8] K Katsaliaki and SC Brailsford. Using simulation to improve the blood supply chain. J. Oper. Res. Soc. 2007; 58, 219-27.

[9] JS Rytilä and KM Spens. Using simulation to increase efficiency in blood supply chains. Manag. Res. News 2006; 29, 801-19.

[10] NV Dijk, R Haijema, JVD Wal and CS Sibinga. Blood platelet production: A novel approach for practical optimization. Transfusion 2009; 49, 411-20.

[11] G Sahin, S Meral and H Süral. Locational analysis for regionalization of Turkish Red Crescent blood services. Comput. Oper. Res. 2007; 34, 692-704.

[12] V Hemmelmayr, KF Doerner, RF Hartl and MWP Savelsbergh. Delivery strategies for blood products supplies. OR Spectrum 2009; 31, 707-25.

[13] KE Kendall. Formulating blood rotation policies with multiple objectives. Manag. Sci. 1980; 26, 1145-57.

[14] V Bosnes, M Aldrin and HE Heier. Predicting blood donor arrival. Transfusion 2005; 45, 162-70.

[15] GB Schreiber, UK Sharma, DJ Wright, SA Glynn, HE Ownby, Y Tu, G Garratty, J Piliavin, T Zuck and R Gilcher. First year donation patterns predict long-term commitment for first-time donors. Vox Sang. 2005; 88, 114-21.

[16] J Beliën and H Forcé. Supply chain management of blood products: A literature review. Eur. J. Oper. Res. 2012; 217, 1-16.

[17] RL Ritchie and DV Marshall. Business Risk Management. Chapman Hall, London, 1993.

[18] T Aven. A unified framework for risk and vulnerability analysis covering both safety and security. Reliab. Eng. Syst. Safe 2007; 30, 745-54.

[19] JG March and Z Shapira. Managerial perspectives on risk and risk taking. Manag. Sci. 1987; 33, 1404-18.

[20] BL Londe. Supply chain management: Myth or reality? Supply Chain Manag. Rev. 1997; 1, 6-7.

[21] VR Tummala, MM Nkasu and KB Chuah. A framework for project risk management. ME Rese. Bull. 1994; 2, 145-71.

[22] C Harland, R Brenchley and H Walker. Risk in supply networks. J. Purch. Supply Manag. 2003; 9, 51-62.

[23] U Jüttner, H Peck and M Christopher. Supply chain risk management: Outlining an agenda for future research. Int. J. Logist. Res. Appl. 2003; 6, 197-210.

[24] I Vanany, S Zailani and N Pujawan. Supply chain risk management: Literature review and future research. Int. J. Inform. Syst. Supply Chain Manag. 2009; 2, 16-33.

[25] S Rao and TJ Goldsby. Supply chain risks: A review and typology. Int. J. Logist. Manag. 2009; 20, 97-123.

[26] C Colicchia and F Strozzi. Supply chain risk management: A new methodology for a systematic literature review. Supply Chain Manag. Int. J. 2012; 17, 403-18.

[27] A Xanthopoulos, D Vlachos and E Iakovou. Optimal newsvendor policies for dual-sourcing supply chains: A disruption risk management framework. Comput. Oper. Res. 2012; 39, 350-7.

[28] PR Sinha, LE Whitman and D Malzahn. Methodology to mitigate supplier risk in an aerospace supply chain. Supply Chain Manag. Int. J. 2004; 9, 154-68.

[29] TG Noordewier, G John and JR Nevin. Performance outcomes of purchasing arrangements in industrial buyer-vendor relationships. J. Market. 1990; 54, 80-93. 
http://wjst.wu.ac.th

[30] G Souter. Risks from supply chain also demand attention. Bus. Insur. 2000; 34, 26-8.

[31] HL Lee, V Padmanabhan and S Whang. Information distortion in a supply chain: The bullwhip effect. Manag. Sci. 1997; 43, 546-58.

[32] XA Koufteros, MA Vonderembse and TJ Doll. Examining the competitive capabilities of manufacturing firms. Struct. Equ. Model. 2002; 9, 256-82.

[33] Y Lin and L Zhou. The impacts of product design changes on supply chain risk: A case study. Int. J. Phys. Distr. Logist. Manag. 2011; 41, 162-86.

[34] O Tang and SN Musa. Identifying risk issues and research advancements in supply chain risk management. Int. J. Prod. Econ. 2011, 133, 25-34.

[35] A Samvedi, V Jain and FT Chan. Quantifying risks in a supply chain through integration of fuzzy AHP and fuzzy TOPSIS. Int. J. Prod. Res. 2013, 51, 2433-42.

[36] CS Tang. Perspectives in supply chain risk management. Int. J. Prod. Econ. 2006; 103, 451-88.

[37] $\mathrm{R}$ Tummala and $\mathrm{T}$ Schoenherr. Assessing and managing risks using the supply chain risk management process (SCRMP). Supply Chain Manag. Int. J. 2011; 16, 474-83.

[38] J Hallikas, I Karvonen, U Pulkkinen, VM Virolainen and M Tuominen. Risk management processes in supplier networks. Int. J. Prod. Econ. 2004; 90, 47-58.

[39] PR Kleindorfer and GH Saad. Managing disruption risks in supply chains. Prod. Oper. Manag. 2005; 14, 53-68.

[40] D Bandaly, A Satir and L Shanker. Integrated supply chain risk management via operational methods and financial instruments. Int. J. Prod. Res. 2013; 52, 2007-25.

[41] SM Wagner and V Silveira-Camargos. Managing risks in just-in-sequence supply networks: Exploratory evidence from automakers. IEEE T. Eng. Manag. 2012; 59, 52-64.

[42] VM Grötsch, C Blome, and MC Schleper. Antecedents of proactive supply chain risk management: A contingency theory perspective. Int. J. Prod. Res. 2013; 51, 2842-67.

[43] A Chaudhuri, BK Mohanty and KN Singh. Supply chain risk assessment during new product development: A group decision making approach using numeric and linguistic data. Int. J. Prod. Res. 2013; 51, 2790-804.

[44] A Diabat, K Govindan and VV Panicker. Supply chain risk management and its mitigation in a food industry. Int. J. Prod. Res. 2012; 50, 3039-50.

[45] M Vedel and C Ellegaard. Supply risk management functions of sourcing intermediaries: An investigation of the clothing industry. Supply Chain Manag. Int. J. 2013; 18, 509-22.

[46] B Gaudenzi and A Borghesi. Managing risks in the supply chain using the AHP method. Int. J. Logist. Manag. 2006; 17, 114-36.

[47] JP Vilko and JM Hallikas. Risk assessment in multimodal supply chains. Int. J. Prod. Econ. 2012; 140, 586-95.

[48] M Goh, JY Lim and F Meng. A stochastic model for risk management in global supply chain networks. Eur. J. Oper. Res. 2007; 182, 164-73.

[49] R Hemaida. A practical model to audit risk assessment in a health-care setting. Manag. Audit. J. 1995; 10, 37-41.

[50] S Kavanagh and J Cowan. Reducing risk in health-care teams: An overview. Clin. Govern. Int. J. 2004; 9, 200-4.

[51] MI Okoroh, BD Ilozor and PP Gombera. Modelling of risk management in health care facilities. Facilities 2006; 24, 197-210.

[52] WP Pierskalla, RJ Sassetti, BC Director and IL Chicaqo. Regionalization of Blood Banking Services. National Health Care Management Center, University of Pennsylvania, 1980.

[53] K Katsaliaki. Cost-effective practices in the blood service sector. Health Pol. 2008, 86, 276-87.

[54] JS Rytilä and KM Spens. Using simulation to increase efficiency in blood supply chains. Manag. Res. News 2006 29, 801-19.

[55] D Delen, M Erraguntla, RJ Mayer and CN Wu. Better management of blood supply-chain with GISbased analytics. Ann. Oper. Res. 2011, 185, 181-93. 
http://wjst.wu.ac.th

[56] MJ Fontaine, YT Chung, WM Rogers, HD Sussmann, P Quach, SA Galel, LT Goodnough and F Erhun. Improving platelet supply chains through collaborations between blood centers and transfusion services. Transfusion 2009; 49, 2040-7.

[57] IN Pujawan and LH Geraldin. House of risk: A model for proactive supply chain risk management. Bus. Process Manag. J. 2009; 15, 953-67.

[58] W Widiasih, PD Karningsih and U Ciptomulyono. Development of integrated model for managing risk in lean manufacturing implementation: A case study in an Indonesian manufacturing company. Proc. Manufac. 2015; 4, 282-90.

[59] C Kasemset, J Wannagoat, W Wattanutchariya and KY Tippayawong. A risk management framework for new product development: A case study. Indus. Eng. Manag. Syst. 2014; 13, 203-9.

[60] D Anggrahini, PD Karningsih and M Sulistiyono. Managing quality risk in a frozen shrimp supply chain: A case study. Proc. Manufac. 2015; 4, 252-60.

[61] T Kusmantini, AD Guritno and HC Rustamaji. Mapping of supply chain risk in industrial furniture base on house of risk framework. Eur. J. Bus. Manag. 2015; 14, 104-15.

[62] A Shahin. Integration of FMEA and the Kano model: An exploratory examination. Int. J. Qual. Reliab. Manag. 2004; 21, 731-46.

[63] JR Hauser and DP Clausing. The house of quality. Harvard Bus. Rev. 1988; 66, 63-73.

[64] JB Jennings. Blood bank inventory control. Manag. Sci. 1973; 19, 637-45.

[65] $\mathrm{H}$ Min and WB Yu. Collaborative planning, forecasting and replenishment: Demand planning in supply chain management. Int. J. Inform. Tech. Manag. 2008; 7, 4-20.

[66] SHW Stanger, R Wilding, N Yates and S Cotton. What drives perishable inventory management performance? Lessons learnt from the UK blood supply chain. Supply Chain Manag. Int. J. 2012; 17, 107-23. 